\title{
¿Cómo valoran los diputados su presencia en las redes sociales?: Análisis de la utilización de Internet en el Congreso de los Diputados durante la X Legislatura
}

\section{How do Members of Parliament value their presence in the Social Media? 10th term Spanish Parliament Internet Use Analysis}

\author{
Belén Andueza López. Universidad Nebrija (mandueza@nebrija.es)
}

Rocío Alejandra del Cerro de Utrilla. Doctoranda de la UNED (rdelcerro@rociodelcerro.net)

Recibido: 4-V-2015 - Aceptado: 13-X-2015

Resumen:

El estudio analiza la valoración que hacen los diputados sobre el uso de Internet, situándolo como instrumento de comunicación, deliberación y consulta para su actividad parlamentaria. Para ello se procede al análisis de las respuestas de los diputados al cuestionario enviado para estudiar su actividad en las redes sociales. Las conclusiones apuntan a una progresiva consolidación de la red como instrumento de comunicación política. Los principales retos derivan de la falta de formación y práctica por parte de políticos y ciudadanos para encontrar cauces que conviertan los parlamentos digitales en parlamentos abiertos ${ }^{1}$.

Palabras clave:

Internet; parlamento; participación política; redes sociales; diputados.

Abstract:

The study analyzes Members of Parliament's assessment on Internet use as communication, deliberation and consultation instrument for parliament activity. In order to do so we have analyzed the replies from the members of parliament to the questionnaire sent to study their activity in the Social Media. Conclusions indicate a gradual consolidation of Internet as political communication instrument. The main challenges derive from the lack of training and practice both from politicians and citizens to find ways that would turn digital parliaments into open parliaments ${ }^{2}$.

Keywords:

Internet; Parliament; Political Participation; Social Media; Members of Parliament.

1 Concepto desarrollado a través de diversos estudios en el libro de mismo nombre Parlamentos abiertos, coordinado por Rafael Rubio $\mathrm{y}$ al que haremos posteriores referencias.

2 Concept developed through different studies in the book with the very name of Open Parliaments, coordinated by Rafael Rubio and to which we shall further refer to. 


\section{Introducción}

Se cumplen 20 años de la utilización de Internet por parte de los partidos políticos en España. En un principio su presencia se limitó a las páginas web 1.0 de tipo mural o expositivo, que adoptaban la estética de las vallas publicitarias en época electoral. Con el inicio del siglo XXI nace el concepto web $2.0^{3}$, que ofrece cauces de mayor interactividad entre representantes y representados. La realización y los resultados obtenidos por la campaña Obama 2.0 en 2008 en Estados Unidos supusieron un punto de inflexión. Es a partir de entonces cuando los partidos y los diputados, individualmente considerados, comienzan a percibir la progresiva importancia de Internet para la política. Su uso se ha ido extendiendo de forma progresiva, incluso más allá de las campañas electorales (Rey Morató, 2007; Caldevilla, 2009; Rubio, 2009, 2014; Beas, 2011; Álvarez y Rodríguez, 2014; Rubio 2009, 2014).

Las elecciones generales de 2008 supusieron el inicio del uso político de la red por parte de un reducido número de diputados. La campaña de las elecciones generales de 2011 fue la de la explosión del consumo de Internet y redes sociales a través de dispositivos móviles, lo que hizo aumentar su capacidad de impacto y seguimiento (Álvarez y Rodríguez, 2014: 242).

El año 2014 ha marcado un nuevo punto de inflexión con la irrupción en la escena política de los nuevos partidos digitales. Partidos que no forman parte de la X Legislatura, objeto de este estudio, pero que han comenzado a influir en ellos.

La utilización de Internet en política corre pareja a los avances en el uso de la misma por parte de la sociedad española. La multiplicación de dispositivos que permiten acceder a la red, y la paulatina incorporación de la ciudadanía a Internet, propician una mayor participación política online de los partidos y los ciudadanos. Cambios en los usos de Internet que quedan reflejados de forma periódica en los barómetros del Centro de Investigaciones Sociológicas (Anduiza et al. 2010: 136).

A pesar de su novedad, han sido muchos los estudios realizados sobre los orígenes, características y consecuencias de la participación ciudadana en política vía Internet (Surowiecki, 2005; Morozov, 2012; Castells, 2006, 2009; Lévy, 2004a, 2004b). Estudios a los que añadiremos los realizados sobre la actividad de los diputados en la red y su relación con los ciudadanos (Dader, 2001a, 2001b, 2003a, 2003b, 2006, 2007; Eva Campos, 2011; Túñez y Sixto, 2011; Guadián Orta, 2012; Rubio, 2011, 2014; Álvarez y Rodríguez, 2014).

Desde perspectivas complementarias, se han efectuado múltiples estudios sobre las brechas digitales y democráticas (Robles, 2009; Cáritas, 2008; Cantijoch et al., 2010; Norris. 2003), y también sobre el carácter predictivo de la red y su potencial

3 El origen de la web 2.0 se sitúa en 1999, con la puesta en línea de Napster, las primeras aplicaciones para la publicación de blogs como blogger y la creación de la Wikipedia en 2001. Se trataba de un nuevo modo de concebir la world wide web. El concepto web 2.0 debe su origen a Tim O` Reilly en 2004. 
para recabar feedback y datos de los representados (Tusmajan, 2010; Congosto, Fernández y Moro, 2011; Deltell, 2012; Bond, Faris, y Jones, 2012).

También destacan por su continuidad y actualidad los realizados en blogs de estudiosos de la política 2.0, los informes de Fundación Telefónica y diversos organismos e instituciones como el ya citado CIS, o el Estudio General de Medios, además de congresos y organizaciones internacionales como la UIP (Organización Interparlamentaria cuya sede se encuentra en Ginebra).

Sin embargo, la peculiaridad de este estudio radica en el interés de las investigadoras por conocer de primera mano, con preguntas abiertas que permitan evidenciar las inquietudes y la subjetividad de los entrevistados, cómo se ven a sí mismos utilizando, gestionando, acogiendo o rechazando los beneficios y las dificultades de la red: su proximidad, su falta de reflexión, la ausencia de filtros y la capacidad volitiva que supone. Internet no es obligatorio, lo que sí es obligatorio es estar ahí.

\subsection{Hipótesis}

Durante la X Legislatura los políticos, de forma individual, se incorporan progresivamente a la utilización de las redes sociales para incrementar los cauces de comunicación, deliberación y consulta con los ciudadanos con el fin de mejorar su actividad parlamentaria. Un uso que comienza a dar sus primeros resultados y a poner de manifiesto los obstáculos a superar.

\subsection{Objetivos}

El objetivo del estudio es saber cómo valoran los diputados del Congreso la utilización de Internet en su trabajo parlamentario. Se trata de conocer y analizar si utilizan las redes para incorporar las inquietudes de los ciudadanos a su quehacer en la política y si el interés de estos queda reflejado en sus actividades parlamentarias.

\subsection{Estado de la cuestión}

Un sucinto repaso del trabajo de los diputados en el Congreso señala que su actividad offline se halla enmarcada en dos funciones: una legislativa, para la presentación, discusión, aprobación o rechazo de futuros proyectos de ley; y otra de control al Gobierno, ya sea de forma ordinaria a través de las preguntas o interpelaciones; o de forma extraordinaria por medio de la cuestión de confianza, moción de censura o reprobación contra ministros.

En España, el peso de los partidos sigue siendo enormemente relevante en la vida política. Las listas cerradas, la obediencia al partido, la idea de clase, la sumisión a las estrategias del aparato han provocado que la figura del diputado quede 
diluida en la formación a la que pertenece. Los gabinetes de comunicación y prensa, siguiendo las directrices de las ejecutivas de los partidos, tienen como misión trazar las líneas de actuación de los mismos. Una condición que comienza a quebrarse sutilmente con la incorporación voluntaria de los políticos a la red, que les permiten establecer relaciones personales y fuera de las órbitas de influencia de los aparatos del partido.

En el estudio cronológico acerca de la configuración del Parlamento 2.0 ofrecido por Eva Campos (2014) se insiste en que los Parlamentos siempre han tenido la pretensión de explorar y utilizar las innovaciones tecnológicas para potenciar la relación entre representantes y representados. Desde la primera etapa que denomina de "Parlamento electrónico" hasta la actual, que denomina de "Parlamento abierto", Campos destaca que Internet ha concedido a los parlamentarios la posibilidad de promocionarse y dirigirse directamente a los ciudadanos, recuperando así un protagonismo que habían perdido a favor de los grupos parlamentarios (2014: 40).

La permanente evolución tecnológica, que ha generalizado el uso de los móviles como herramienta desde la que tener acceso a las redes sociales, ha favorecido la expansión de las mismas. Ha conducido de la "política presencial" a la "política de bolsillo" (Gutiérrez Rubí, 2015: 57). El 22 de julio de 2014, el BOE recogía la licitación del contrato de telefonía móvil y otros servicios del Congreso de los Diputados, incluyendo teléfonos de última generación, tarifa plana y líneas de $\mathrm{ADSL}^{4}$ en sus domicilios por valor de 624 mil euros al año. Se trata del ejemplo palpable del interés de las instituciones por dotar a sus representantes de los medios necesarios para incrementar su comunicación con la ciudadanía.

Antoni Gutiérrez Rubí ha hecho en su página web el seguimiento de la actividad de los políticos en las redes sociales. "El widget es un directorio online para el activismo político y la comunicación digital, una herramienta sencilla para conocer de primera mano quiénes son, qué herramientas utilizan y cuál es la actividad online de los senadores y senadoras, así como de dónde son y de qué partido" (Gutiérrez Rubí, 2014a). Los listados sobre la utilización de las redes sociales por parte de los políticos están sometidos a oscilaciones de altas y bajas, como consecuencia de la propia naturaleza de la Cámara Baja.

Tomando como base los estudios realizados por Gutiérrez Rubí (2014a) y Álvarez y Rodríguez (2014) se observa que de los 350 diputados que componen la X Legislatura, la mayoría de los que utilizan redes sociales se decantan por Twitter, utilizada por 196, aunque han llegado a tener su perfil activo 215. Por debajo se sitúa el número de diputados presentes en Facebook, red que utilizan 153 diputados y que a pesar de encontrarse por detrás de Twitter es la que más ha incrementado el número de perfiles en esta Legislatura, que comenzó con 90 parlamentarios usuarios de Facebook.

\footnotetext{
4 Dicha información fue ampliamente recogida por numerosos y muy diversos medios de comunicación: Elboenuestrodecadadía.com, 22 julio 2014. Telecinco, Informativos, 22 julio 2014. Elconfidencial.com, 22 julio 2014.
} 
La tendencia que expresa una preferencia por Twitter evidencia el interés de los representantes por tener una relación con los representados, rápida y basada en titulares, más que cuentas en Facebook que exigen un mayor esfuerzo de continuidad y una mayor dotación de tiempo y reflexión.

A estos datos hay que añadir otra tendencia de uso en Internet por parte de los diputados: la participación en plataformas externas relacionadas con la actividad parlamentaria tales como OsOigo, Change y Kuorum.

El premio Parlamentario 2.0 de 2013 fue Carles Campuzano, diputado de CIU, que tiene blog desde 2006, cuenta en Facebook, Twitter, Instagram, Linkedin, canales en Youtube y Vimeo y participación en la plataforma social Change.org.:

"La red refuerza el perfil individual; permite a quien quiere expresar su visión personal, más allá del previsible, aunque seguramente necesario, argumentario del partido. Tengo la impresión que cada vez más los ciudadanos esperan de sus representantes políticos este tipo de actitudes que, por otro lado, chocan con una legislación electoral que da todo el poder a los partidos y a los grupos parlamentarios. Ahí tenemos un asunto pendiente e imprescindible para renovar la vitalidad democrática de nuestro sistema político"5.

Hay una tensión comunicativa no resuelta entre los partidos que desean aplicar un control más férreo y los diputados, muchos de ellos experimentados usuarios digitales, dispuestos a usar la red y aceptar los códigos de la misma: compartir información, ofrecer respuestas, dar una visión más personal, y recibir información por parte de los ciudadanos.

Una tensión de tipo interno, entre sujetos y organizaciones, que podría ser finalmente dinamitada por la fuerza de las nuevas tecnologías, destinadas a cambiar de forma radical la forma de entender y vivir la realidad. "Vivimos en un momento en el que las tecnologías evolucionan a un ritmo tan acelerado que una aplicación como WhatsApp, que se popularizó en el año 2012, ha cambiado todos los estándares de la comunicación vía móvil” (Andueza, Pérez, 2013: 21).

\section{Metodología}

Para la realización de este estudio se ha optado por un diseño exploratorio. Ello permite la aproximación al hecho social que se trata de investigar: la utilización de Internet por parte de los diputados en el Congreso como herramienta de comunicación política, directa y horizontal con el ciudadano. Para ello se han tenido en cuenta los análisis previos realizados por Dader (2003 a), Dader y Campos (2006) y Campos (2011).

El diseño exploratorio ha hecho posible el contacto con esta realidad y determinar líneas futuras de investigación, así como dimensiones de análisis y posibles variables explicativas y explicadas.

5 Se trata de un premio que conceden los periodistas acreditados en el Congreso de los Diputados. Carles Campuzano resultó premiado y sus palabras sobre el mismo fueron recogidas en http://politicosenred.com/entrevista-carles-campuzano-diputado-ciu-premioparlamentario-2-0.html 
La elección de la estrategia se ha basado en la integración de técnicas de recogida de información y, en concreto, lo que Bericat (1998) llama "combinación”.

\subsection{Metodología en la primera fase}

\subsubsection{Revisión bibliográfica: literatura escrita sobre el tema}

Este estudio trata de analizar el binomio "diputados" e "Internet". El Parlamento se ha convertido en foco de multitud de estudios que analizan las repercusiones de la red en la vida política (Gonzalo Rozas y Ramos Vielba, 2000a, 2000b, 2001; Dader 2001a, 2001b, 2003a, 2003b; Marcos y Rovira, 2006; Cantijoch, 2011; Gutiérrez-Rubí, 2014a, 2014b; Lobera y Rubio, 2014), con especial atención al estudio de redes sociales (Deltell, 2012; Caldevilla, 2009) así como el protagonismo de estas en la concepción de "Parlamento abierto", concepto ampliamente tratado en el manual del mismo nombre coordinado por Rafael Rubio (2014).

A estos hay que añadir los blogs, conferencias y artículos que siguen de cerca estos temas, así como las recomendaciones de diversos congresos, conferencias u organismos como ALICE o la UIP, entre otros.

\subsubsection{Análisis de datos secundarios}

Destacaremos los estudios y barómetros ofrecidos por el CIS que pueden ser consultados en su página web: Estudio CIS n. ${ }^{\circ}$ 2736: “Internet y participación política 2007”; los datos ofrecidos por los barómetros del CIS sobre los usos de Internet: Estudio CIS n. ${ }^{\circ}$ 2889: "Actitudes hacia las tecnologías de la información y la comunicación", de mayo 2011; Estudio CIS n. ${ }^{\circ}$ 2.948, barómetro de junio de 2012; Estudio CIS n. ${ }^{\circ}$ 2987, barómetro de mayo de 2013; Estudio CIS n. ${ }^{\circ} 3038$, barómetro de septiembre de 2014. A ellos añadimos los datos del Estudio General de Medios, los informes anuales de Fundación Telefónica y los estudios de IAB Spain.

Las técnicas de recogida de información utilizadas en una primera fase han sido de gran ayuda para poner en marcha la segunda fase del estudio, que se apoya en la encuesta como estrategia de investigación. Gutiérrez Rubí (2014a) y Álvarez y Rodríguez (2014) han estudiado los perfiles de los diputados en esta X Legislatura. De los mismos se deriva un interés creciente de los parlamentarios por la política 2.0. El uso de las redes desbanca a los correos electrónicos y los blogs. Twitter es la red más utilizada, 196 de los 350 diputados la utilizan, frente a los 153 de Facebook (Álvarez y Rodríguez, 2014: 45). La media de edad de los diputados que las utilizan es de 50 años; los menores de 40 tienen mayor presencia en la red, pero se aprecia el interés de los mayores de 60 años por incorporarse a ellas. Por sexos, se percibe una diferencia a favor de los hombres en el uso de las redes, pero no se aprecia una brecha de género significativa. Por adscripción ideológica es mayor la participación de los representantes de los partidos minoritarios y las formaciones de izquierda. 


\subsection{Metodología en la segunda fase}

Se ha puesto en marcha una encuesta virtual, que será la estrategia fundamental, y un cuestionario, la técnica de recogida de información más importante. El cuestionario está estructurado pero con preguntas abiertas ${ }^{6}$.

\subsubsection{Diseño del cuestionario}

Entrevista estructurada (es decir, las mismas preguntas para todos, la misma formulación y el mismo orden) con preguntas abiertas que se inspiraron en cuestionarios utilizados anteriormente.

\subsubsection{Trabajo de campo}

Se envió el cuestionario a toda la población (350 diputados) en tres etapas:

- $\quad 1 .{ }^{\text {a }}$ etapa: envío por $e$-mail los correos electrónicos particulares de los diputados. Este proceso tuvo una duración de un mes (15 de octubre a 15 de noviembre de 2014).

- $\quad$ 2. etapa: envío del mismo cuestionario a los asistentes de sus señorías en los grupos parlamentarios para que se lo hicieran llegar a aquellos que no tenían publicado su correo en la página web del Congreso (1-15 de noviembre de 2014).

- $\quad 3 .^{\text {a }}$ etapa: envío a los organismos oficiales donde trabajan diputados que son ministros, asesores o altos cargos, como es el caso del presidente del Gobierno, la vicepresidenta, el jefe de Gabinete del presidente del Gobierno y el secretario de Estado de Relaciones con las Cortes en el Ministerio de Presidencia (1-15 noviembre de 2014).

\section{Resultados}

El primer resultado es la baja participación de los diputados en este estudio. Solo 33 de 350 enviaron las respuestas.

Del análisis de las preguntas formuladas se deduce que el Congreso, como parte representativa de la sociedad, va adoptando los mismos usos y costumbres que los ciudadanos a los que representan.

No hay una percepción clara en cuanto al valor que tiene Internet como emisor de ideas y como contenedor de productos, pero sí como herramienta de trabajo propia para mantener la escucha activa, el feedback con los representados, y la incorporación de sus inquietudes en el trabajo legislativo.

Se trata de un comportamiento propio de los periodos de transición hacia una nueva forma de hacer política, basada en una interacción voluntaria con los particulares que no es percibida como obligatoria sino como actitud de vanguardia por

$6 \quad$ Se puede consultar en el Anexo I. 
parte de unos pocos. Son los políticos los que deciden cómo, a quién y por qué responder a unas preguntas y no a otras, manteniendo el poder sobre los tiempos y el objeto de deliberación.

Los partidos políticos siguen teniendo a la televisión tradicional como referente de su presencia ante los electores y de instrumento de propaganda, cuando la propia televisión ya ha dado pasos en su aprovechamiento y convergencia con Internet. Como indican Suárez y Andueza, "las cadenas españolas ya no tienen una simple página institucional donde se presenta la programación, sino que han convertido sus webs en sitios desde los que se puede acceder a la emisión en vivo y a determinados programas en archivo" (Suárez y Andueza, 2014: 34). Desde esta perspectiva es necesario añadir que los políticos y los partidos son cada vez más conscientes de la importancia de las acciones simultáneas televisión/Internet cuando estos intervienen en programas que tienen sus propios hashtag. Circunstancia que es aprovechada como espacio de apoyo y propaganda hacia el político y sus siglas.

Las disfunciones en el uso de Internet podrían deberse, en parte, a que todavía existe una brecha generacional en las personas que deciden las políticas comunicativas de los partidos políticos, ancladas en formas de comunicación que han sido sobrepasadas o incluidas en otros formatos gracias a las nuevas tecnologías de la comunicación.

Este artículo avala la idea de que el futuro de las redes es presente, que los políticos no pueden sustraerse a la realidad tecnológica que nos circunda, y que la lucha contra la desafección pasa por una mayor interacción entre el Parlamento y la calle, como forma de dotar de mayor transparencia, efectividad y rapidez el trabajo de los diputados.

Han sido 33 de los 350 diputados los que han respondido al cuestionario enviado, el 9,4\%. Los datos de principio de legislatura (para evitar los posibles cambios producidos por las altas y bajas en la Cámara Baja) cifraban en 226 los escaños ocupados por varones $(64,6 \%)$ y 124 el número de mujeres $(35,4 \%)$. Comparando dichos porcentajes con los obtenidos en el estudio, observamos que han colaborado 24 varones, lo que supone un 72,72\% de la participación, mientras que han sido nueve las mujeres, dejando el porcentaje en $27,27 \%$. Estas diferencias de género coinciden con la falta de paridad en el Congreso, que confirma la existencia de una brecha digital de género y mayor interés de los varones por las nuevas tecnologías. Respecto a los datos globales, han respondido al estudio el 10,61\% de los diputados y el 7,25\% de las diputadas.

Por grupos: hemos obtenido dos respuestas del Grupo Mixto, dos varones: un representante de Amaiur, y otro de Compromís. En UPyD solo nos ha respondido un diputado, también varón. En el Grupo Catalán hemos obtenido dos respuestas, en este caso de un varón y de una mujer. Izquierda Plural ha sido el grupo más numeroso en sus aportaciones; nos han contestado más de la mitad de sus representantes. Siguiendo la tónica general, también en Izquierda Plural la mayoría de las respuestas fueron de varones, 5 diputados frente a una sola diputada. El Grupo Popular ha sido el que menos respuestas ha aportado; solo respondieron a nuestras preguntas cuatro varones y tres mujeres. Por fin, en el Grupo Socialista contestaron 15 diputados, 11 de ellos varones y cuatro mujeres. 
Cuadro 1: Participación de Grupos Parlamentarios en el estudio

\begin{tabular}{|c|c|c|c|}
\hline Grupos parlamentarios & Varones & Mujeres & Representación \% \\
\hline G. Socialista (110) & 11 & 4 & $13,7 \%$ \\
\hline G. Popular (185) & 4 & 3 & $3,7 \%$ \\
\hline G Izquierda Plural (11) & 5 & 1 & $54,4 \%$ \\
\hline Grupo Catalán (16) & 1 & 1 & $12,5 \%$ \\
\hline Grupo UPyD (5) & 1 & & $11,1 \%$ \\
\hline Grupo Mixto( 18) & 2 & 9 & $9,4 \%$ \\
\hline Total (350) & 24 & 9 & \\
\hline
\end{tabular}

Fuente: Elaboración propia

En cuanto a la variable de la edad, esta parece ser determinante en la utilización de las redes sociales. Como señalan Álvarez y Rodríguez (2014: 249), el hecho de que haya más diputados que senadores en las redes sociales podría deberse al hecho de que la edad media del Congreso es de 51,5 años frente a los 53,1 años del Senado. De igual manera, son los diputados más jóvenes (40 años o menos), los que más utilizan Facebook y Twitter. Afirmación que, sin embargo, también debe tener en cuenta los datos sobre consumo de redes entre la población española, que apuntan a elevados índices de incorporación de mayores de 60 años al uso de estas nuevas herramientas (Álvarez y Rodríguez, 2014: 251).

Aunque el reducido número de diputados que ha accedido a formar parte de esta muestra podría provocar un sesgo de la misma, los datos obtenidos sí muestran una tendencia en cuanto a la implicación y utilización de los políticos que utilizan las redes para relacionarse con los ciudadanos.

El hecho de que el Grupo Parlamentario más proclive a la colaboración haya sido Izquierda Plural, alcanzando 54,4\%, coincide con los estudios acerca de que los sectores más proclives a utilizar Internet para entablar discusiones políticas son los que se ubican ideológicamente en la izquierda (Anduiza et al.: 2010; Álvarez y Rodríguez, 2014). La formación que menor representación porcentual tiene en el estudio es el Grupo Popular, muy por debajo de la media de cada partido, con un 3,7\%. Su escasa participación podría formar parte de una inclinación al silencio provocada por el especial desgaste que la crisis económica y los casos de corrupción han provocado en el partido que sustenta al Gobierno.

El cuestionario comenzaba con una serie de preguntas cerradas que tenían un doble objetivo: permitir una primera entrada en el tema y establecer el mapa de la utilización de las redes sociales por parte de los diputados. 
Cuadro 2: Análisis de las redes utilizadas

\begin{tabular}{|c|c|c|c|}
\hline Grupos & Facebook & Twitter & Otras redes \\
\hline Grupo Socialista & 15 & 15 & 2 \\
\hline Grupo Popular & 5 & 7 & 1 \\
\hline Grupo Izquierda Plural & 5 & 5 & 1 \\
\hline Grupo Catalán & 2 & 2 & \\
\hline Grupo UPyD & 2 & 2 & 4 \\
\hline Grupo Mixto (Amaiur, Comprimís) & 29 & 32 & \\
\hline Total & & & \\
\hline
\end{tabular}

Fuente: Elaboración propia

Las respuestas, a pesar de su número reducido, coinciden con los resultados expuestos anteriormente por Álvarez y Rodríguez (2014). Son los partidos de Izquierda los que mayor presencia tienen en las redes sociales, mostrando preferencia por Twitter respecto a Facebook. El hecho de que exista tan poca diferencia entre los usuarios de Facebook (29) y Twitter (32) implica que los diputados que han contestado son los que cumplen el target de "usuarios early adopters", los más avanzados. Lo cual denota que la vía de comunicación directa por Internet entre ciudadano y diputado es muy minoritaria.

En cuanto a las preguntas de respuesta abierta, estos son los resultados:

\section{Con las redes, ì ha aumentado el número y la calidad de sus relaciones con los ciudadanos?}

Todos los participantes han respondido de forma afirmativa. Entre los ítems señalados figuran: la ventaja de la red para poner en contacto a políticos y ciudadanos; su inmediatez, que resulta ágil para señalar las opiniones de la calle pero que puede anular la reflexión; y una preocupación por cerrar totalmente la brecha digital en España.

Datos que coinciden con el “Informe sobre política y redes sociales" de 2011 realizado por la agencia Intelligence Compass, en el que se analizaban las relaciones entre los particulares y políticos en las redes sociales. El 94\% las consideraba muy útiles y el 78\% de los políticos consideraban que las redes eran un medio excelente para llegar a la ciudadanía (Túñez y Sixto, 2011; Álvarez y Rodríguez, 2014).

Las distintas respuestas convergen en la perspectiva mantenida por David Álvarez (2014) en su blog Parlamento 2.0 cuando señala que ya no es suficiente estar en Internet, sino que es necesario saber estar; y que esa presencia óptima y profunda de un político en Internet debe responder a dos preguntas: qué puede aprender el político de la ciudadanía y qué le puede ofrecer. 
Alejandro Fernández, del Grupo Popular, usuario de Facebook y Twitter, asegura que gracias a las redes se ha comunicado directamente con unas dos mil personas y hay unas doscientas con las que mantiene una comunicación diaria o semanal; algo, asegura, que le sería imposible realizar presencialmente. En su cuenta de Facebook, donde cuenta con 5.000 amigos o seguidores, ha realizado propuestas que han recibido múltiples comentarios y que a su vez han sido contestados por el diputado popular.

María Valentina Martínez Ferro, del mismo grupo político, es usuaria de la microred desde 2007. Tiene 790 seguidores y afirma que "en Twitter, por ejemplo, el contacto es directo. Contestan los ciudadanos y protestan en directo". Resalta así las características de inmediatez y claridad de esta red, que la convierten en la preferida por los políticos.

Gaspar Llamazares, desde el grupo Izquierda Plural, cuantifica el crecimiento de las relaciones: "Se han multiplicado por diez en cantidad y calidad, me ha permitido contrastar y recibir o enviar información en tiempo real”. La afirmación se explica al comprobar que Llamazares es uno de los diputados con mayor presencia en la red. Tiene perfil en Flickr, Youtube, Facebook y en Twitter, donde alcanza los 250 mil seguidores.

Joan Baldoví también avala la utilidad de las redes sociales: "Desde Compromís hacemos una política de proximidad que se basa en las interacciones con los ciudadanos. Por ejemplo, en el Congreso tramitamos muchas preguntas que nos llegan a través del portal http:/ queremossaber.net, donde desde Compromís ponemos nuestros grupos institucionales al servicio del ciudadano para que puedan hacer llegar sus preguntas directamente a los organismos responsables. Otro ejemplo pudiera ser las preguntas que transmitimos de los ciudadanos al entonces ministro Cañete sobre los incendios que hubo en el verano en la zona de Valencia. La intervención se puede ver aquí: http://youtu.be/kur6yXA0DTQ y está compuesta casi en su integridad por las preguntas que la gente me hizo llegar a través de las redes".

Desde el Grupo Parlamentario Socialista, Félix Lavilla, usuario de las redes sociales Facebook y Twitter, destaca la capacidad de escucha de los parlamentarios: "Tengo un espacio, Parlamento Abierto Soria, donde los ciudadanos me pueden enviar propuestas y sugerencias, algunas de ellas se convierten en iniciativas parlamentarias (que cito en la formulación o planteamiento), como se puede comprobar".

\section{2. ¿Cree que la presencia en las redes solo se incrementa en los periodos electorales?}

De las 33 respuestas, 23 han sido afirmativas, siete negativas y tres no saben. Datos que podrían avalar la creencia generalizada de que políticos y ciudadanos se sienten más concernidos por la política durante las campañas electorales y más propensos a mantener debates o encuentros en las redes sociales.

Algunos de ellos manifiestan que fue a raíz de unas elecciones, cuando comenzaron a tener perfiles y a hacerlos más visibles en las redes. La mayoría expresa dos condiciones que les parecen imprescindibles para tener una buena y honesta presencia en la red: mantener los perfiles activos y el rechazo a los políticos que solo los utilizan para conseguir votos, o 
que utilizan la figura de community manager y no son ellos mismos los que hacen los comentarios. De igual modo, destacan el deseo de que la unión entre votantes y políticos a través de la red se haga cotidiana para tener acceso a la opinión de la ciudadanía.

Lourdes Ciuró, del Grupo Catalán afirma: "No me parece correcto tener presencia en las redes sólo en época de campaña. Denota una forma antigua de concebir la política y la relación con los electores”. El estudio de su presencia en Facebook desde 2008 corrobora su presencia continua en la red, más allá de las campañas electorales, en las que sin embargo incrementa el número de post $\mathrm{o}$ entradas.

Por su parte, Cayo Lara, del Grupo Izquierda Plural, escribe: "Anteriormente sí sucedía eso. Los candidatos creaban sus perfiles para las redes sociales durante las campañas y luego se olvidaban de mantenerlos y darles continuidad. Pero en la actualidad creo que la presencia de políticos en las redes se ha normalizado como un elemento más del trabajo político diario. Han empezado a ser un canal más a través del que comunicarse”. De hecho, en Facebook tiene más de 73 mil seguidores; y en Twitter 200 mil seguidores y casi catorce mil tuits, lo que denota un trabajo continuo en las redes.

En este mismo sentido, César Luena, desde el Grupo Socialista, asegura que "es impensable una campaña sin redes, pero es más impensable aún apartar a las redes del día a día. No hay dos mundos, uno online y otro off, hay solo uno”. César Luena tiene actividad en Facebook con seis mil seguidores, y trece mil en Twitter.

\section{3. ¿Cree que las redes hacen a la sociedad más participativa y consciente de la política?}

La respuesta es afirmativa pero con una multiplicidad de matices, que se mueven desde el desconcierto hacia las nuevas formas de participación digital y no presencial de los ciudadanos; al temor a las críticas anónimas, irreflexivas o destructivas que pululan por la red.

Cayo Lara indica que "no podemos pretender que la participación política se quede en hacer click desde el ordenador de casa o mandar un tuit desde un teléfono". César Luena alerta del carácter impulsivo de las redes que impide una reflexión pausada de los problemas, pero destaca su papel de correa de transmisión entre políticos y ciudadanos.

Todos ellos creen que ayudaría a rebajar el índice de desafección política, aunque alertan del mal uso que se hace de ella, de la falta de respeto con la que son tratados en ocasiones, de las distorsiones que producen y de la existencia de brecha digital por la edad. Ninguno de ellos alude a los reducidos niveles de interacción que se recoge en sus páginas, donde la presencia de la ciudadanía se ve en los "me gusta", pero no en la existencia de comentarios.

En este punto es interesante observar el nivel de respuesta de los políticos con quienes les mencionan o escriben, porque esto permite conocer su compromiso real con la política 2.0 y el diálogo abierto con los ciudadanos. En los estudios sobre la utilización de Twitter, se verifica que a pesar del incremento de tuits que se escriben, el nivel de respuesta es bajo. En el 
Senado emiten una respuesta por cada 16 menciones recibidas y en el Congreso 1 de cada 43; datos que, sin embargo, deben tener en cuenta el sesgo de la popularidad, ya que hay políticos que pueden recibir miles de menciones diariamente, y que no pueden ser respondidas en su totalidad (Álvarez y Rodríguez, 2014: 261).

Con todo, la principal conclusión que se extrae, es que es el tema que se difunde el que provoca mayores o menores índices de interacción. Esta es mucho menor cuando los mensajes se limitan a reflejar la agenda, y se incrementa cuando se aluden a temas de interés para el ciudadano o se realizan propuestas donde la sociedad se siente concernida.

En otro orden de cosas, persiste el respeto a los medios de comunicación tradicionales, propio de una fase intermedia en el modo de entender los nuevos canales de comunicación. En este sentido, Sixto Iglesias, del Grupo Izquierda Plural, añade: "Los medios de comunicación de masas siguen teniendo un protagonismo fundamental".

\section{4. ¿Tiene usted en cuenta las peticiones y los comentarios que recibe en la red en su trabajo parlamentario?}

El planteamiento de la pregunta conduce a una respuesta que es siempre afirmativa. Los diputados se ven claramente concernidos por las informaciones de la calle para incluirlas, dicen, en sus reflexiones, peticiones, preguntas, proyectos.

Y se repite de nuevo un sesgo en las respuestas de los diputados y es a propósito de las descalificaciones que reciben. Figura, por ejemplo, en las palabras del diputado Ayllón, del Grupo Popular: "Cuando son razonables, claro. Porque, lamentablemente, a veces te encuentras con comentarios que son insultantes".

Alusión a las ofensas que durante la X legislatura han recibido los políticos -particularmente de los dos partidos mayoritarios- vía Internet. Seguidamente y como señal de su confianza en la red, José Luis Ayllón, actual secretario de Estado de Relaciones con las Cortes, hace notar que él fue el primer diputado en tener cuenta en Twitter, que comenzó con la frase "Estoy en el Congreso". En la actualidad cuenta con 5.700 seguidores.

También desde el Grupo Socialista, José Ignacio Sánchez Amor responde: "Recibimos continuas peticiones, sugerencias y quejas (también de vez en cuando alguna cosa ofensiva, pero va en el sueldo)". Aunque el propio diputado lo recoge entre paréntesis, adjudicándole un tono coloquial, la respuesta denota un cansancio personal e intelectual por el hecho de ser o "tener que ser" blanco de las críticas en Internet. Tono similar al que encontramos en su página de Twitter, donde tiene 4.500 seguidores. En ella debajo de su foto se lee: “Diputado (perdón por haber nasío)”. Se trata de una expresión popular que pone de manifiesto la etapa de crítica padecida por la clase política.

En otro orden de cosas, destacan dos respuestas. Proceden de muy diferentes lugares del arco parlamentario, pero coinciden en la utilidad de saber, conocer y poner cara a los problemas de la calle, para que estos sean llevados y mejor tratados en el hemiciclo. Dos respuestas que avalan la utilidad de las redes sociales para humanizar la política y la función del legislativo. 
Destaca la respuesta del diputado Carlos Martínez Gorriarán, portavoz adjunto del Grupo UPyD: "Por supuesto. En mi caso, a raíz de conversaciones en Twitter he llegado a presentar numerosas iniciativas en el Congreso de los Diputados que nos parecían muy razonables. Desde preguntas parlamentarias hasta proposiciones no de ley, como el caso de una mujer llamada Elena Alfaro que nos trasladó una propuesta para la creación y el mantenimiento de un sistema de préstamo gratuito de libros de texto para la educación básica en centros sostenidos con fondos públicos. Su iniciativa la presentamos en el Congreso y fue aprobada e incluso fue incluida como enmienda en la última ley educativa, LOMCE”.

Desde el Grupo Izquierda Plural, Gaspar Llamazares reconoce: "La mitad de mis preguntas parlamentarias, al menos, provienen de las redes sociales y en particular de la página web y de Twitter”, donde como mencionábamos, tiene 250 mil seguidores.

\section{5. ¿Cree que la política cambiará en el futuro debido a la existencia de la red y los avances tecnológicos? iHabrá una de- mocracia más participativa, más inmediata, con partidos fuertes o débiles?}

Es sin duda la respuesta más difícil del cuestionario, por cuanto exige un mayor acto de voluntad, de redacción y de participación por parte del diputado. La respuesta global es afirmativa en los diputados y el presidente del Congreso. Se produce una conciencia de cambio real, pero distintos análisis de los caminos y el protagonismo de los partidos políticos.

Un primer grupo de respuestas se centra en el futuro y la fuerza de los partidos: José Ignacio Sánchez Amor, del Grupo Socialista, señala: "Sí, habrá una democracia más participativa, y no sé cómo afectará a los partidos, aunque es seguro que creará relaciones con los ciudadanos con menor intermediación partidaria. También tiene riesgos el activismo de sofá, que deja tranquilas las conciencias y vacías las manifestaciones callejeras".

Otro diputado compañero de filas, Víctor Morlán, aboga por los partidos fuertes: "Lo que espero y deseo es que la combinación del debate y participación en los partidos con las nuevas formas tecnológicas de comunicación consoliden partidos fuertes, pues son las bases de un sistema democrático como el español”. Una tercera vía dentro del Partido Socialista es la que habla de adaptación; Sebastián Franquis Vera asegura que los partidos que se adapten a los cambios tecnológicos se harán más fuertes y los que no, más débiles.

En la misma línea de partidos fuertes se sitúa el diputado de Izquierda Plural Joan Coscubiela: "A mi juicio, si los ciudadanos se movilizan, habrá partidos fuertes". Desde el Grupo Popular, Alejandro Fernández responde: "Se producirá una democratización de las estructuras internas de los partidos, lenta pero inexorable. A su vez, los liderazgos serán más cortos por la presión que sufrirá una clase política que vivirá más exigencia que nunca. Pero los partidos sobrevivirán”.

Otro tipo de reflexiones incide en la transparencia y en la utilidad de los partidos políticos como centralizadores de los problemas de la calle. No puede obviarse el hecho de que este cuestionario se realiza y envía en otoño de 2014, un momento de especial tensión ciudadana por los casos de corrupción que derivan en desafección. En este sentido, Federico Buyolo, 
del Grupo Socialista, explica: "Esa debe ser la tendencia. Inexorablemente, la política actual no puede no tener en cuenta a los movimientos de las redes sociales".

Respuesta similar es la ofrecida desde Izquierda Plural por Cayo Lara: "Para que haya una democracia más participativa lo principal es la concienciación de los ciudadanos, que se sientan incumbidos por la política y por lo que en ella se decide. Que se mejoren los canales de participación debe servir como herramienta para conseguir esa mayor concienciación e interés de la sociedad. Una de las claves será la transparencia y la proactividad de las instituciones para que los ciudadanos vuelvan a creer en ellas y se vaya acabando el desprestigio que arrastran de un tiempo a esta parte".

Desde el mismo Grupo, Gaspar Llamazares apunta: “Existe la posibilidad de completar la política representativa con una mayor participación y decisión ciudadana, pero depende de la organización de los ciudadanos en la red y de los cambios imprescindibles en las instituciones y en particular en los reglamentos de las cámaras parlamentarias".

Desde Amaiur, en el Grupo Mixto, Xabier Mikel Errekondo Saltsamendi reflexiona: “¿Democracia más participativa? Menos es imposible. Pero para llegar a un estado en que la ciudadanía sienta que se cuenta con ella para la toma de decisiones estructurales más allá del voto cada cuatro años, hay una cierta distancia. Pues ello supondría la articulación de mecanismos permanentes que garantizaran la participación, cosa a la que temen enormemente aún los grandes partidos".

Espera con la que no coincide Lourdes Ciuró, del Grupo Catalán: "La política no puede esperar al futuro para cambiar. Debe abordar su actualización y adecuación a la realidad del presente de forma inmediata. Y no solo la política, los políticos. Mayor presencia en la calle y en las redes. Mayor obligación de rendir cuentas de la actividad realizada y mayor apertura en los sistemas de elección a los representantes públicos".

Carlos Martínez del Grupo UPyD escribe: "No habrá democracia de calidad sin partidos políticos transparentes y con democracia interna".

Una tercera vertiente de respuestas es la que incide en los problemas mismos de la red, su incontinencia verbal, su inmediatez, su falta de rigor para ser el medio de transmisión entre ciudadanos y políticos. Desde el Grupo Popular, el diputado Ayllón afirma: "Creo que sí, pero solo si conseguimos que la tolerancia y el rigor se hagan más presentes. Mientras no sea así, la credibilidad de las redes sociales como medio de transmisión de ideas estará muy dañada”.

En el Grupo Socialista, Joan Ruiz i Carbonell insiste: “Eso sí, no podemos sustituir la democracia por "lo que circula por las redes", porque, entre otras cosas, no es mesurable".

Multiplicidad de opiniones que coinciden con las diversas teorías sobre la utilización de las redes en la vida política. La vertiente más optimista, considera que los partidos políticos están perdiendo el privilegio de la acción política y que la política online favorece el activismo gradual, a la carta, espontáneo, organizado, solitario o en red, (Gutiérrez Rubí, 2014c); los pe- 
simistas, como Morozov (2012), explican el desengaño de Internet, y los representantes de una tercera vía que defienden que Internet no va a cambiar la forma de gobierno, pero sí abrir mayores espacios de información, comunicación, deliberación y participación de los ciudadanos en su relación con los poderes públicos (Rubio, 2014: 397).

\section{Conclusiones}

La primera conclusión es que con carácter general las redes han llegado al Parlamento, encontrándonos en un proceso de transformación hacia lo que se ha dado en llamar “Parlamentos abiertos” (Rubio, 2014), más transparentes, participativos y abiertos a la colaboración.

Se verifica el interés de políticos y ciudadanos por encontrar esferas de colaboración que mejoren la eficacia y la utilidad de la vida parlamentaria. Una "política de proximidad”, en palabras de Gutiérrez Rubí: “La monitorización, la escucha y la adecuación nos dan las claves para estructurar y diseñar los nuevos comportamientos de la actividad parlamentaria” (2014b: 369).

Un reto que tiene obstáculos en su camino. El primero de ellos haría referencia a la falta de aprovechamiento de las nuevas tecnologías para procurar un diálogo real y más efectivo entre representantes y representados. La confusión existente entre las páginas institucionales, de partidos, y las redes de los parlamentarios, la dificultad de los ciudadanos para comprender los tecnicismos y encontrar los temas que le interesan, la dificultad para seguir los avatares de la vida parlamentaria son algunos de los retos apuntados por Rafael Rubio:

Por un lado vemos cómo los diputados no están familiarizados con las tecnologías, los ciudadanos no están familiarizados con las tecnologías ni con el proceso legislativo, y los técnicos, centrados muchas veces en que el sistema técnico funcione sin preocuparles mucho el para qué, no entienden, por lo general, ni a los parlamentarios ni a los ciudadanos (Rubio, 2014: 414).

Todo ello se traduce en una falta de interacción a través de las redes, donde todavía son escasos los debates y comentarios. A pesar de ello, los cinco grupos que han tomado parte en el estudio coinciden en resaltar el valor de la red como canal de comunicación de futuro y los avances tecnológicos como instigadores de una nueva forma de hacer política. La utilización de las redes es considerada clave para la mejora de las relaciones con la sociedad, la lucha contra la desafección política, la impolítica, y un conocimiento más pormenorizado de los problemas de la calle. Perspectiva positiva a la que se añaden, la inmediatez, la facilidad, la individualidad o marca personal, la puesta en valor de su trabajo con correas transmisoras de los intereses de los ciudadanos. Gracias a la red, señalan, las preocupaciones de la calle llegan al hemiciclo transformándose en leyes.

La participación en las redes sociales no es obligatoria, nace del voluntarismo de sus señorías. No hay unas directrices en cuánto a qué redes deben escoger y cómo deben ser diseñadas o atendidas. No se trata de una cuestión baladí; en una de- 
mocracia de partidos fuertes, con identidades sólidas, direcciones de comunicación severas y argumentarios dirigidos, esta falta de regulación acerca del uso de Internet, podría evidenciar que la presencia en redes no se percibe como principal prioridad de las formaciones políticas. Se constata en las políticas de comunicación una ausencia de trabajo planificado y continuo destinado a conseguir un mejor aprovechamiento de las redes. Frente a ello, Álvarez (2014) defiende la creación de una mínima planificación y estrategia en todos los factores y actores que conforman el ecosistema político digital, del que forman parte no solo los políticos, sino los partidos y las instituciones políticas en las que realizan su actividad.

El discurso mantenido por los diputados, a medio camino entre la voluntariedad y el buenismo, resulta propio de periodos de transición en la adopción de nuevos usos en materia de comunicación. Aunque la televisión sigue siendo consideraba el medio favorito para mantener contacto con la ciudadanía y existe una dependencia importante de los medios de comunicación tradicionales, se abre paso la presencia de diputados y periodistas en los nuevos medios digitales: blogs, cuentas de Facebook, Twitter e Instagram. Nuevas tecnologías que les permiten, por una parte, explorar y afianzar redes de comunicación con la sociedad; y, por otra, construir marcas personales con discursos y opiniones propios.

Respecto al perfil de los diputados digitales, los resultados de nuestra muestra coinciden con otros anteriores (Campos, 2011; Álvarez y Rodríguez, 2014; Gutiérrez Rubí, 2014), que señalaban una preeminencia en el uso de Internet de los diputados varones, de izquierda y formaciones minoritarias. En lo que se refiere a este estudio, de las 33 personas que han respondido al cuestionario, 21 han sido de formaciones políticas situadas a la izquierda, 8 de derecha y 4 de formaciones minoritarias.

Por género, ha sido mayor la implicación de los hombres que de las mujeres en este estudio, 72,27\% frente a 27,27\%, evidenciando la existencia de una brecha de género entre los participantes. La ausencia de paridad en la encuesta es fiel reflejo de la realidad del hemiciclo. Tomando como referencia los datos globales que, según los perfiles ofrecidos al inicio de legislatura (226 diputados y 124 diputadas), han respondido al estudio el 10,61\% de los diputados y el 7,25\% de las diputadas.

La edad media de los parlamentarios internautas se sitúa en los 50 años, "aunque se aprecia que los más mayores no son completamente ajenos a este fenómeno, como podría pensarse a priori” (Álvarez y Rodríguez, 2014: 250).

En cuanto a la red social escogida, los diputados se decantan por Twitter, a pesar de que la red más empleada en España es Facebook, 196 frente a 153. La elección podría deberse a la inmediatez que ofrece el uso de tuits con 140 caracteres. Así se condensa la información en titulares listos para ser retuiteados, viralizados, enlazados y utilizados a un tiempo por políticos, periodistas y ciudadanos. Información que parece dejar en suspenso la contradicción a la que aluden los políticos: la incapacidad de las redes para ofrecer una reflexión y explicación sosegada. Twitter se caracteriza por ser una red ca- 
liente, que provoca una rápida conexión entre emisor y receptor, basada en la inmediatez, el impulso y el titular sin ulteriores explicaciones.

El cambio generacional favorece que el interés por las nuevas tecnologías sea creciente: "Las redes son una oportunidad y para mi generación forman parte del día a día, son una forma más de comunicación”, dice César Luena, diputado del Grupo Socialista. Y lo son a pesar de las imperfecciones y de los temores que provoca la comunicación dialógica; diálogo continuo más allá de las campañas electorales e invitación a la participación ciudadana. Se entiende como un rincón de veracidad y por ello se rechazan las imposturas, los perfiles falsos y los mensajes realizados por gestores de prensa.

Las innovaciones tecnológicas han obligado a una adaptación permanente de los canales de información entre periodistas y políticos, usuarios y gestores de redes, que ofrecen a un tiempo inmediatez, cooperación e individualidad: las redes sociales permiten que unos y otros puedan expresarse al margen del grupo parlamentario o el grupo mediático al que representan.

Respecto al futuro, el estudio refleja los cambios que las nuevas tecnologías supondrán para los partidos políticos: mayor deliberación, participación y posibilidad de listas abiertas. Un camino que se considera incipiente.

En las respuestas, hay una defensa mayoritaria del status quo, de la continuidad de los partidos políticos tal y como los conocemos, con ciertas peticiones de avances en cuanto a su democracia interna. Solo dos de los diputados que han participado en este estudio han mostrado su deseo de un cambio radical en la forma de hacer política; los demás piden cambios paulatinos.

Ampliando la perspectiva, las preguntas abiertas planteaban si las tecnologías influirán en la forma de entender la democracia. Analizando los tres estadios de la misma en relación a la utilización de Internet, podríamos hablar de una primera fase de deliberación, otra de acción y una última de democracia directa o voto continuado.

Parece claro que estaríamos en una fase embrionaria de democracia deliberativa; la escasa implicación de ciudadanos y políticos no induce por el momento al sueño utópico de Lévy sobre la formación de una inteligencia colectiva (Lévy 2004a, 2004b, 2007) basada en tecnologías y no en partidos. No existe el concepto de ciberciudadano; el ciberactivismo de sofá no sustituye por ahora al contacto directo. Sí se intuye un deseo por parte de unos y otros de provocar espacios de encuentro más allá de frías páginas electorales, aumentar la temperatura de la red alentando las conversaciones.

El reducido grupo de parlamentarios que participan en el estudio pone de manifiesto cierta falta de implicación en los estudios sobre redes (Campos, 2011). Otras explicaciones más autocríticas incidirían en la decisión de las investigadoras de utilizar como única vía de recogida de datos el correo electrónico. Una herramienta que, según ha quedado expuesto en anteriores trabajos como los de Eva Campos y José Luis Dader, podrían estar eventualmente saturadas por campañas de bombardeo masivo de dichos buzones que hace que muchos estén bloqueados y sean poco usados por los parlamenta- 
rios. Una segunda opción sería la apuntada por Álvarez y Rodríguez cuando señalan que el incremento de las redes sociales ha llevado aparejado un descenso en el uso de los correos electrónicos. Un error que deberá ser claramente subsanado en la metodología utilizada en futuros estudios.

La ausencia de parlamentarios del Grupo Popular podría deberse, como se ha sugerido anteriormente, al contexto social -experimentado en la fecha de este estudio, otoño de 2014- de crítica y rechazo a las políticas del Gobierno que han llevado a sus diputados a mayores índices de retraimiento y silencio en los medios de comunicación, sean estos tradicionales o de nuevas tecnologías.

El estudio basado en un cuestionario de preguntas abiertas ha permitido recoger palabras y pensamientos propios, establecer caminos que deberían ser más transitados. Solo el estudio comparativo entre diputados de distintas legislaturas reflejará los cambios de actitud de los propios diputados respecto al uso y utilidad de las nuevas tecnologías.

Este artículo avala la idea de que el futuro de las redes es presente, que los políticos no pueden sustraerse a la realidad tecnológica que nos circunda y que la lucha contra la desafección pasa por una mayor interacción entre el Parlamento y la calle, como forma de dotar de mayor transparencia y efectividad el trabajo de los diputados.

Nuevos partidos como Podemos, que no ha formado parte del Congreso de los Diputados en la X Legislatura, pero que ha comenzado a irrumpir en la escena política española a raíz de las Elecciones Europeas de 2014, han puesto de manifiesto cómo las redes pueden potenciar el desarrollo de los movimientos ciudadanos y su conversión en partidos políticos, así como nuevas formas de interacción entre representantes y representados.

Los cambios tecnológicos están generando nuevas aptitudes y actitudes por parte de políticos y ciudadanos que repercuten en la creación de nuevas formas de hacer política. Un punto de inflexión que deberá ser estudiado estableciendo estudios comparativos entre los partidos y los diputados de la X y la XI Legislatura, que ahonden en los pasos que deberá dar el Congreso para abrir sus puertas de par en par.

\section{Referencias bibliográficas}

Álvarez, D. y Rodríguez, R. (2014): “Parlamentarios 2.0: presencia y actividad de diputados y senadores españoles en las redes sociales”, en Rubio, R. (coord.): Parlamentos Abiertos. Tecnología y redes para la democracia. Madrid: Congreso de los Diputados, pp. 235-276.

Álvarez, D. (2014): “¿Político reputado en Internet? Urgente y necesario. Reputación online (1), en Parlamento 2.0. Disponible en: http://parlamento20.es/politico-reputado-en-Internet-urgente-y-necesario-reputacion-online-i\#more-9539 [Consultado el 22/IX/2015]. 
Andueza B. y Pérez, R. (2013): "El poder de las nuevas tecnologías: el móvil como herramienta para el nuevo periodista”, en Rodríguez Terceño, J. (coord.): Nuevas perspectivas modales para la enseñanza superior. Madrid: Visión Libros, pp. 1938.

Anduiza, E. et al. (2010): “Los usos políticos de Internet en España”, Revista española de Investigaciones Sociológicas (REIS), n. 129, pp. 133-146.

Beas, D. (2011): La reinvención de la política. Obama, Internet y la nueva esfera pública. Barcelona: Península.

Bericat, E. (1998): La integración de los métodos cuantitativo y cualitativo en la investigación social. Barcelona: Ariel.

Berrocal, S.; Redondo, M. y Campos, E. (2011): “Una aproximación al estudio del infoentretenimiento en Internet: origen, desarrollo y perspectivas futuras”, AdComunica: revista científica de estrategias, tendencias e innovación en comunicación, n. 4, pp. 63-79.

Bond, R., Farris, C., \& Jones, J. (2012): A 61-million-person experiment in social influence and political mobilization. McMillan Publishers Limited, 489 (7415), pp. 295-298.

Caldevilla, D. (2009): “Democracia 2.0: La política se introduce en las redes”, Pensar en la publicidad, vol. III, n. 2, pp. 3148.

Campos, E. (2011): El desarrollo de la ciberdemocracia en el congreso de los diputados: la comunicación e interacción entre ciudadanos y parlamentarios a través de Internet (2004-2008) [Tesis doctoral. Facultad de Ciencias de la Información. Universidad Complutense de Madrid].

- (2014): “Historia del Parlamento 2.0”, en Rubio, R. (coord.): Parlamentos Abiertos. Tecnología y redes para la democracia. Madrid: Congreso de los Diputados, pp. 31-60.

Cantijoch et al (2010): Internet y participación política en España. Opiniones y actitudes. Madrid: CIS, n. 63.

Cáritas, Fundación Foessa (2008): “VI informe sobre exclusión y desarrollo social en España 2008”. Disponible en: http://www.caritas.es [Consultado el 15/09/2014].

Castells, M. (2005): “Internet y la sociedad red”, en Moraes D. (coord.): Por otra comunicación: los media, globalización cultural y poder. Barcelona: Icaria.

- (2006): La sociedad en red: una visión global. Madrid: Alianza editorial.

- (2009): Comunicación y poder. Madrid: Alianza editorial.

Congosto, M.; Fernández, L. y Moro. M. (2011): “Twitter y política: información, opinión y ipredicción?”, Cuadernos Evoca, n. 4, Comunicación política 2.0, pp. 11-17.

Dader, J. L. (2001a): “La ciberdemocracia posible: reflexión prospectiva a partir de la experiencia en España”, CIC, Cuadernos de información y comunicación, n. 6, pp. 177-220. 
- (2001b): “Ciberdemocracia: el mito realizable”, Palabra Clave, n. 4, pp. 35-50.

- (2003a): “Ciberdemocracia y ciberparlamento: el uso del correo electrónico entre los parlamentarios españoles y los ciudadanos comunes (1999-20019)”, Telos. Cuadernos de comunicación, tecnología y sociedad, n. 55, pp. 86-96.

- (2003b): “Ciberdemocracia y comunicación política virtual: el futuro de la ciudadanía electrónica tras la era de la televisión”, en Berrocal, S. (coord.): Comunicación política en televisión y nuevos medios. Barcelona: Ariel, pp. 309-342.

Dader J. L. y Campos, E. (2006): “Internet parlamentario en España (1999-2005): los recursos para el contacto ciudadano y su uso, con una comparación europea”, ZER, n. 20, pp. 105-132.

Dader, J. L y Díaz Ayuso, I. (2007): “Las webs de los partidos políticos españoles 2004-2005. Una investigación preliminar y de comparación europea, con una propuesta metodológica”, [II Congreso de Comunicación Política. Madrid, Universidad Complutense de Madrid, 8 y 9 de marzo].

Deltell, L. (2012): "Estrategias de comunicación política en las redes sociales durante la campaña electoral del 2011 en España: el caso de Equo". Disponible en: http://eprints.ucm.es/15544/1/equo\%2CLIBROeprint.pdf. [Consultado el $16 / 3 / 2014]$.

Esposito, R. (2006): Categorías de lo impolítico. Buenos Aires: Kattz.

Gonzalo Rozas, M. A. y Ramos Vielba I. (2000): “La documentación parlamentaria en Internet: el caso de la página web del Congreso de los Diputados”, Revista de las Cortes Generales, n. 50, pp. 305-330.

- (2000b): "La documentación parlamentaria en Internet (II): el caso de las páginas web de las Asambleas Legislativas de la Comunidades Autónomas”, Revista de las Cortes Generales, n. 51, pp. 217-251.

- (2001): "La documentación parlamentaria en Internet (y III): el caso de las páginas web en los países de la Unión Europea”, Revista de las Cortes Generales, n. 53, pp. 319-352.

Guadián Orta, C.; Rangel Pardo, F. y Linares Salas, J. (2012): “Análisis de Redes de Influencia en Twitter”, [II Congreso Español de Recuperación de Información. Valencia, junio de 2012]. Disponible en: http://users.dsic.upv.es/grupos/nle/ceri/papers/ceri2012_guardian.pdf

Gutiérrez-Rubí, A. (2014a): Parlamentos 2.0. Disponible en: http://www.gutierrez-rubi.es [Consultado el 22/10/2014].

- (2014b): "Parlamento abierto y política de proximidad", en Rubio, R. (coord.): Parlamentos Abiertos. Tecnología y redes para la democracia. Madrid: Congreso de los Diputados, pp. 363-388.

- (2014c): Tecnopolítica. Disponible en: http://www.gutierrez-rubi.es/tecnopolitica/

- (2015): La transformación digital y móvil de la comunicación política. Barcelona: Ariel.

Lévy, P. (2004a): Ciberdemocracia. Ensayo sobre filosofía política. Barcelona: OUC.

- (2004b): Inteligencia colectiva. Disponible en: http://inteligenciacolectiva.bvsalud.org [Consultado el 2/09/2014]. 
- (2007): Cibercultura. Informe al consejo de Europa. Barcelona: Anthropos.

Lobera, J., Rubio, R. (2014): “Nativos digitales. ¿̇Hacia una nueva participación política?”. [Ponencia presentada en ALICE] Disponible en: http://www.alice-comunicacionpolitica.com/abrir-ponencia.php?f=517-F5421305c5171411461212ponencia-1.pdf [Consultado el 15/VII/2015].

Marcos, M. C. y Rovira, C. (2006): "Las webs parlamentarias: funciones y elementos de su interfaz en el acceso a la información”, Revista española de Documentación científica, vol. 29, n. 1, pp. 13-35.

Morozov, E. (2012): El desengaño de Internet. Barcelona: Destino.

Norris, P. (2001): Digital divide. Civil engagement, information poverty and the Internet worldwide. Cambridge: Cambridge University Press.

- (2003): Democratic Phoenix: reinventing political Activism. Cambridge: Cambridge University Press.

Rey Morató, J. del (2007): Comunicación Política, Internet y Campañas Electorales. De la Teledemocracia a la Ciberdemocracia. Madrid: Tecnos.

Robles, J. M. (2009): Ciudadanía digital. Una introducción a un nuevo concepto de ciudadano. Barcelona: UOC.

Rubio, R. (2009): “Quiero ser como Obama (me pido una red social)”, Cuadernos de Pensamiento Político, n. 21, pp.123-154.

- (2011): “Nuevas tecnologías y transparencia parlamentaria”, Cuadernos de Comunicación Evoca, n. 4, pp. 23- 27.

- (2014): “Knocking on the Parliaments door (Parlamentos digitales en la era de la participación)”, en Rubio, R. (coord.): Parlamentos Abiertos. Tecnología y redes para la democracia. Madrid: Congreso de los Diputados, pp. 389-418.

Suarez F. y Andueza, B. (2014): La comunicación televisiva ante el fenómeno de Internet: EEUU, Europa y España. Disponible en: www.foro2014.com/wp-content/uploads/.../34.-Suárez-y-Andueza.pdf. [Libro en galeradas].

Surowiecki, J (2005): Cien mejor que uno. Barcelona: Urano.

Túñez, M. y Sixto, J. (2011): “Redes sociales, política y compromiso 2.0: la comunicación de los diputados españoles en Facebook”, Revista Latina de Comunicación Social, n. 66, pp. 210-246.

Tumasjan, A. et al. (2010): "Predicting elections with Twitter: what 140 characters reveal about political sentiment", Proceedings of the Fourth International Conference on Weblogs and Social Media, Washington: AAAI Press, pp. 178-185.

\section{Otros recursos digitales consultados:}

http://www.congreso.es/portal/page/portal/Congreso/Congreso/Informacion/InfoParlam [Consultado 17/10/2014]

https://www.facebook.com/GPPopular?sk=wall. [Consultado 24/10/2014]

http://www.socialistasdelcongreso.es/opencms/opencms/gps [Consultado 24/10/2014]

http://www.ciucongreso.es [Consultado 28/10/2014] 
http://congreso.eaj-pnv.eu/esp/participa_quejate.php [Consultado 28/10/2014]

http://weblogs.upyd.es/congreso/contacto [Consultado 29/10/2014]

http://politicosenred.com/entrevista-carles-campuzano-diputado-ciu-premio-parlamentario-2-0.html [Consultado $10 / 11 / 2014]$

http://www.cis.es/cis/opencms/ES/index.html [Consultado 2014]

\section{ANEXO I: Cuestionario enviado a los diputados de la X Legislatura}

1. ¿ ¿Tiene usted página web?

2. $\quad$ iTiene usted blog?

3. ¿Qué redes sociales utiliza (Linkedin, Facebook, Twitter...)?

4. Con las redes, ¿̨ha aumentado el número y la calidad de sus relaciones con los ciudadanos?

5. ¿Cree que la presencia en las redes solo se incrementa en los periodos electorales?

6. ¿Cree que las redes hacen a la sociedad más participativa y consciente de la política?

7. ¿Tiene usted en cuenta las peticiones y los comentarios que recibe en la red en su trabajo parlamentario?

8. ¿Cree que la política cambiará en el futuro debido a la existencia de la red y avances tecnológicos?

9. ¿ ¿Habrá una democracia más participativa, más inmediata, con partidos fuertes o débiles? 